\title{
Transdermal Delivery of Hyaluronan Tetrasaccharide by Constant Current Iontophoresis
}

Madoka Kage and Yoshihiro Tokudome*

Laboratory of Dermatological Physiology, Faculty of Pharmaceutical Sciences, Josai University, 1-1 Keyakidai, Sakado, Saitama, 350-0295, Japan

\begin{abstract}
It is well known that scars, wrinkles, and intraarticular diseases such as rheumatoid arthritis can be healed by injecting hyaluronan (HA) into the skin and joints. However, based on its varying molecular size, skin penetration of HA may be limited. In this study, we aimed to investigate the effect of transdermal enhancements such as electroporation (EP) and iontophoresis (IP) on the in vitro skin permeability of HA tetrasaccharide (HA4) to deliver HA4 into skin effectively. The effects of EP and IP on the skin permeation of HA4 were studied in in vitro skin permeation experiments. Cumulative amounts of HA4 through full-thickness skin after $6 \mathrm{~h}$ were $0.3 \mu \mathrm{g} / \mathrm{cm}^{2}$ for passive diffusion, $2.3 \mu \mathrm{g} / \mathrm{cm}^{2}$ after application of EP (100 V, $10 \mathrm{~ms}, 50$ times), $2310.7 \mu \mathrm{g} / \mathrm{cm}^{2}$ after application of IP (cathodal IP, $0.1 \mathrm{~mA} / \mathrm{cm}^{2}$ ), and $797.9 \mu \mathrm{g} / \mathrm{cm}^{2}$ after application of IP (cathodal IP, $0.05 \mathrm{~mA} / \mathrm{cm}^{2}$ ), respectively. The skin permeability of the IP (cathodal IP, $0.1 \mathrm{~mA} / \mathrm{cm}^{2}$ ) treatment was about 7700 and 1000 -fold increased than that of passive diffusion and the EP treatment. The cumulative amount of HA4 through stripped skin after $6 \mathrm{~h}$ was $1384.3 \mu \mathrm{g} / \mathrm{cm}^{2}$ for passive diffusion. The skin permeability of the cathodal IP (full-thickness skin, $0.05 \mathrm{~mA} / \mathrm{cm}^{2}$ ) treatment was about 1.7 -fold increased than that of passive diffusion (stripped skin). We showed that cathodal IP is useful for delivering HA4 into skin effectively.
\end{abstract}

\section{Publication History:}

Received: August 26, 2015

Accepted: October 12, 2016

Published: October 14, 2016

\section{Keywords:}

Hyaluronan tetrasaccharide, Skin permeation, Iontophoresis

\section{Abbreviations}

HA: Hyaluronan, HA4: Hyaluronan tetrasaccharide, EP: Electroporation, IP: Iontophoresis

\section{Background}

The barrier function of skin is principally attributed to the stratum corneum. Only low molecules, usually less than $500 \mathrm{Da}$, can penetrate the skin membrane. Many approaches including chemical enhancers, thermal methods, electroporation (EP) [1], iontophoresis (IP) [2,3], sonophoresis, laser ablation, and microneedles have been developed to enhance the permeability of drugs into the skin by changing the stratum corneum microstructure. EP is thought to increase the skin permeation of drugs by creating new pores or pathways in the stratum corneum. Structural changes induced by EP application to the skin are related to the production of water-soluble domains or aqueous pathways, which can be applied to the transdermal delivery of hydrophilic macromolecules. IP is a process that enhances the delivery of drugs through a biological membrane via the application of a low-intensity electrical current. IP is the application of an electrical potential that maintains a constant electric current across the skin and enhances the delivery of drugs.

Hyaluronan (HA) is a large, linear polymer of repeating disaccharide units composed of $N$-acetyl-D-glucosamine and $\mathrm{D}$-glucuronic acid. It is a non-sulfated glycosaminoglycan with a molecular weight of over 1,000 kDa. HA is a structural component of the extracellular matrix in a variety of tissues and plays a key role in tissue organization and homeostasis, including angiogenesis, branching morphogenesis, cell migration, and cell proliferation [4-6] It is well known that scars and wrinkles can be healed by injecting HA into the skin. The analgesic effects of intraarticular injection of HA have been immensely beneficial to patients with joint diseases such as osteoarthritis or rheumatoid arthritis. However, It may do bacterial infection by the needle while it has the advantage that it is treatment in a short amount of time. In contrast, IP and EP of HA were used for non-invasive treatment. Therefore, advantage of use of IP and EP were little worry of the infection. Based on its varying molecular size, the skin passive penetration of HA may be limited. We focused our attention on a HA tetrasaccharide (HA4) containing two units, with a single unit being $N$-acetyl-D-glucosamine and D-glucuronic acid. Our group previously reported that HA4 permeated through the skin by passive diffusion [7]. The purpose of this work was to study the effect of EP and IP on the in vitro skin permeability of HA4 across hairless mice skin to deliver HA4 into skin effectively.

\section{Materials \& Methods}

\section{Materials}

HA4 (99.14\%) (776.3 Da) was used by Glycoscience Laboratories Inc. (Tokyo, Japan). All other chemicals and solvents used were analytical grade.

\section{Animals}

Male hairless mice (HR-1, 7 weeks old, body weight: 23-30 g) were purchased from Hoshino Experiment Animal Center (Ibaraki, Japan). They were housed in rooms where the lighting was automatically regulated on a 12 hour light and dark cycle. All experimental animals had free access to food and water. Every animal experiment was conducted under the guidelines of the Life Science Research Center at Josai University.

"Corresponding Author: Prof. Yoshihiro Tokudome, Laboratory of Dermatological Physiology, Faculty of Pharmaceutical Sciences, Josai University, 1-1 Keyakidai, Sakado, Saitama, 350-0295, Japan; E-mail: tokudome@josai.ac.jp

Citation: Kage M Tokudome Y (2016) Transdermal Delivery of Hyaluronan Tetrasaccharide by Constant Current lontophoresis. Int J Pharma Sci Res 3: 113 doi: http://dx.doi.org/10.15344/2394-1502/2016/113

Copyright: (c) 2016 Kage et al. This is an open-access article distributed under the terms of the Creative Commons Attribution License, which permits unrestricted use, distribution, and reproduction in any medium, provided the original author and source are credited. 


\section{In Vitro HA4 Permeation Experiments}

Permeation studies were conducted with excised intact hairless mouse skin (8-12 weeks old) as a diffusion membrane. To obtain stripped skin, adhesive tape was applied to hairless mouse skin with uniform pressure until the stratum corneum was entirely removed from the skin. A vertical diffusion cell used and study conditions were the same as those previously described [7]. Donor solution was applied with $1 \mathrm{~mL}$ of distilled water containing $0.5 \% \mathrm{HA} 4$ for each. The receiver solution was distilled water (passive and EP) or phosphate-buffered saline (IP).

\section{Application of Electroporation}

Plate type Ag electrodes ( $0.04 \mathrm{~mm}$ thickness) were made from silver rods and plates (Murata Yohaku, Tokyo, Japan), respectively, in our laboratory. Plate electrodes passed on electrically insulated doublefaced adhesive tape. The membrane with the peripheral adhesive layer had a $5.0 \mathrm{~mm}$ distance between both plate electrodes to make an electrode membrane at the donor side. A pulse generator (ECM 820, BTX, San Diego, CA, USA) was used to apply voltage 50 times (one pulse every second). The pulse voltage and duration were $100 \mathrm{~V}$ and $10 \mathrm{~ms}$, respectively. This EP treatment was generally conducted at time zero for skin permeation experiments.

\section{Application of Iontophoresis}

A constant current was applied through $\mathrm{Ag} / \mathrm{AgCl}$ electrodes, connected to a constant current generator (IP-50K, Ito Co., Ltd., Tokyo, Japan). A current density of 0.05 and $0.1 \mathrm{~mA} / \mathrm{cm}^{2}$ was applied for $6 \mathrm{~h}$. The donor chamber held either the anode or cathode in two separate sets of experiments in anode-to cathode (anodal IP) or cathode-to anode (cathodal IP) directions.

\section{Determination of HA4}

The determination of HA4 was performed using a LC/MS system (LCQ DECA XP plus, Thermo Fisher Scientific Inc., MA, USA). The electrospray interface, LC/MS separation, and flow rate were the same as previously reported [7].

\section{Results and Discussion}

The effects of EP and IP on the skin permeation of the $0.5 \%$ HA4 solution were investigated in in vitro skin permeation experiments. It has been reported that plate-plate EP electrodes showed higher permeation of drugs than other electrodes [8]. For this reason, EP was applied using plate-plate electrodes in this study. Cumulative amounts of HA4 through full-thickness skin after $6 \mathrm{~h}$ were $0.3 \pm$ $0.1 \mu \mathrm{g} / \mathrm{cm}^{2}$ for passive diffusion (Figure 1), $2.3 \pm 0.9 \mu \mathrm{g} / \mathrm{cm}^{2}$ after application of EP ( $100 \mathrm{~V}, 10 \mathrm{~ms}, 50$ times), respectively (Table 1$)$. The skin permeability of the EP treatment was about 8-fold increased than that of passive diffusion. In addition, the cumulative amount of HA4 for $6 \mathrm{~h}$ was $2310.7 \pm 703.1 \mu \mathrm{g} / \mathrm{cm}^{2}$ after the application of IP (cathodal IP, current density: $0.1 \mathrm{~mA} / \mathrm{cm}^{2}$ ) (Table 1 ). The skin permeability of the IP treatment was about 7700 -fold increased than that of passive diffusion and about 1000-fold increased than that of the EP treatment. The flux and permeability coefficient of the IP treatment was increased than that of the EP treatment (Table 1). EP is thought to increase the skin permeation of drugs by creating new pores or pathways in the stratum corneum. In contrast, IP enhances drug delivery across the skin by electrorepulsion and electroosmosis. IP employs an electrical potential gradient as the driving force to enhance the permeability of charged and polar drug molecules. This study

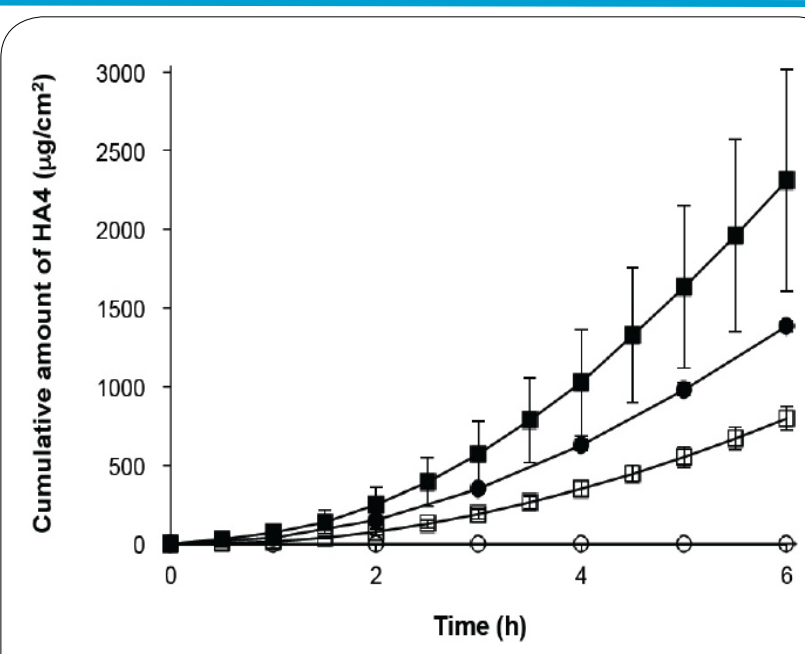

Figure 1. Permeation Profile of the Cumulative Amount of HA4 Each point represents mean \pm S.D. of 3 to 4 determinations. Symbols: passive (full-thickness skin) (o), passive (stripped skin) (0), cathodal IP (current density: $0.05 \mathrm{~mA} / \mathrm{cm}^{2}$ ) ( $\square$ ) and cathodal IP (current density: 0.1 $\left.\mathrm{mA} / \mathrm{cm}^{2}\right)(\mathbf{\bullet})$.

Table 1: Influence of Various Conditions on the Permeation of HA4 through Hairless Mice Skin.

\begin{tabular}{|l|l|l|l|l|}
\hline & Conditions & $\begin{array}{l}\text { Cumulative } \\
\text { amount of HA4 } \\
\left(\mu \mathrm{g} / \mathrm{cm}^{2}\right)\end{array}$ & $\begin{array}{l}\text { Flux }(\mu \mathrm{g} / \\
\left.\mathrm{cm}^{2} / \mathrm{h}\right)\end{array}$ & $\begin{array}{l}\times 10-6 \mathrm{P} \\
(\mathrm{cm} / \mathrm{s})\end{array}$ \\
\hline Passive & $\begin{array}{l}\text { Full-thickness } \\
\text { skin }\end{array}$ & $0.3 \pm 0.1$ & $0.2 \pm 0.1$ & $0.01 \pm 0.005$ \\
\hline Passive & Stripped skin & $1384.3 \pm 32.8$ & $418.0 \pm 30.6$ & $23.2 \pm 1.7$ \\
\hline EP & $\begin{array}{l}100 \mathrm{~V}, 10 \mathrm{~ms}, \\
50 \text { times }\end{array}$ & $2.3 \pm 0.9$ & $0.7 \pm 0.3$ & $0.04 \pm 0.02$ \\
\hline Anodal IP & $0.1 \mathrm{~mA} / \mathrm{cm}^{2}$ & $2.0 \pm 0.1$ & $0.2 \pm 0.1$ & $0.01 \pm 0.007$ \\
\hline Cathodal IP & $0.1 \mathrm{~mA} / \mathrm{cm}^{2}$ & $2310.7 \pm 703.1$ & $656.2 \pm 197.5$ & $36.5 \pm 11.0$ \\
\hline Cathodal IP & $0.05 \mathrm{~mA} / \mathrm{cm}^{2}$ & $797.9 \pm 79.0$ & $236.7 \pm 29.8$ & $13.2 \pm 1.7$ \\
\hline
\end{tabular}

demonstrated that skin permeation of HA4 was enhanced more by IP than that by EP. This may have a great influence on the driving force. The amount of small peptide like arginine-vasopressin (1084.2 Da) permeating through rat skin with the IP treatment was increased than that with passive diffusion, and flux depended on the magnitude of current density [9]. The effect of current density on the transport of HA4 was investigated in in vitro skin permeation experiments by cathodal IP. Cumulative amounts of HA4 permeated after $6 \mathrm{~h}$ were $797.9 \pm 79.0 \mu \mathrm{g} / \mathrm{cm}^{2}$ at $0.05 \mathrm{~mA} / \mathrm{cm}^{2}$ current density and $2310.7 \pm 703.1$ $\mu \mathrm{g} / \mathrm{cm}^{2}$ at $0.1 \mathrm{~mA} / \mathrm{cm}^{2}$ current density, respectively (Figure 1 and Table 1). The skin permeation of HA4 depended on the magnitude of current density. In addition, the cumulative amount of HA4 permeated after $6 \mathrm{~h}$ was $2.0 \pm 0.1 \mu \mathrm{g} / \mathrm{cm}^{2}$ for anodal IP (current density: $0.1 \mathrm{~mA}$ / $\mathrm{cm}^{2}$ ) (Table 1). The skin permeation of the cathodal IP treatment was about 1200-fold enhanced than that of the anodal IP treatment. The delivery of HA4 into the skin was enhanced more by the cathodal IP treatment than that by the anodal IP treatment because the effects of IP on the skin permeation of HA4 of anionic compounds contributed to electrorepulsion. The barrier function of the skin is principally attributed to the stratum corneum. The cumulative amount of HA4 through stripped skin after $6 \mathrm{~h}$ was $1384.3 \pm 32.8 \mu \mathrm{g} / \mathrm{cm}^{2}$ (Figure 1). Skin permeability by passive diffusion was about 4600 -fold increased in stratum corneum stripped skin than that of full-thickness skin. In addition, the cumulative amount of HA4 permeated after $6 \mathrm{~h}$ by cathodal IP (current density: $0.05 \mathrm{~mA} / \mathrm{cm}^{2}$ ) was about $1.7-$ 
Citation: Kage M Tokudome Y (2016) Transdermal Delivery of Hyaluronan Tetrasaccharide by Constant Current Iontophoresis. Int J Pharma Sci Res 3: 113. doi: http://dx.doi.org/10.15344/2394-1502/2016/113

Page 3 of 3

fold increased than that of stripped skin by passive diffusion.

HA has a pronounced hydrophilic capacity and high molecular size polysaccharides; therefore, skin permeation may be limited. Therefore, HA injection therapy is used in cosmetic and medical fields. By contrast, we show that HA4 permeated through the skin by passive diffusion, and cathodal IP was useful for delivering HA4 into skin effectively. Our group previously reported that HA4 enhanced the hyaluronan and collage type I synthesis [10], keratinocyte differentiation [11] and ceramide production [12], and thereby can be involved in the skin functional recovery after UVA irradiation. HA4 delivery into skin by IP may be useful in producing these actions noninvasively.

\section{Conclusion}

We showed that cathodal IP is useful for delivering HA4 into skin effectively.

\section{Competing Interests}

The authors declare that they have no conflict of interest in this work.

\section{Author Contributions}

Conception and design of the experiment: YT.

Performed the experiment: MK.

Analyzed the data: MK.

Wrote the paper: MK, YT.

\section{Refereces}

1. Prausnitz MR, Bose VG, Langer R, Weaver JC (1993) Electroporation of mammalian skin: a mechanism to enhance transdermal drug delivery. Proc Natl Acad Sci U S A 90: 10504-10508.

2. Kalia YN, Naik A, Garrison J, Guy RH (2004) lontophoretic drug delivery. Adv Drug Deliv Rev 56: 619-658.

3. Yan G, Peck KD, Zhu H, Higuchi WI, Li SK (2005) Effects of electrophoresis and electroosmosis during alternating current iontophoresis across human epidermal membrane. J Pharm Sci 94: 547-558.

4. Gakunga P, Frost G, Shuster S, Cunha G, Formby B, et al. (1997) Hyaluronan is a prerequisite for ductal branching morphogenesis. Development 124: 3987-3997.

5. Weigel PH, Hascall VC, Tammi M (1997) Hyaluronan synthases. J Biol Chem 272: 13997-14000.

6. Toole BP, Wight TN, Tammi MI (2002) Hyaluronan-cell interactions in cancer and vascular disease. J Biol Chem 277: 4593-4596.

7. Kage M, Tokudome Y, Hashimoto F (2013) Permeation of hyaluronan tetrasaccharides through hairless mouse skin: an in vitro and in vivo study. Arch Dermatol Res 305: 69-77.

8. Mori K, Hasegawa T, Sato S, Sugibayashi K (2003) Effect of electric field on the enhanced skin permeation of drugs by electroporation. $\mathrm{J}$ Contro Release 90: 171-179.

9. Nair VB, Panchagnula R (2004) Influence of electrical parameters in the iontophoretic delivery of a small peptide: in vitro studies using argininevasopressin as a model peptide. Farmaco 59: 583-593.

10. Kage M, Tokudome $\mathrm{Y}$, Matsunaga $\mathrm{Y}$, Hariya T, Hashimoto $\mathrm{F}$ (2014) Expression of hyaluronan synthase and collagen type I mRNA by hyaluronan tetrasaccharides in normal human dermal fibroblasts. J Jpn Cosmet Sci Soc 37: 1-5.
11. Kage M, Tokudome Y, Matsunaga Y, Hariya T, Hashimoto F (2014) Effect of hyaluronan tetrasaccharides on epidermal differentiation in normal human epidermal keratinocytes. Int J Cosmet Sci 36: 109-115.

12. Kage M, Tokudome $Y$ (2016) Hyaluronan tetrasaccharides stimulate ceramide production through upregulated mRNA expression of ceramide synthesis-associated enzymes. Arch Dermatol Res 308: 95-101. 